\title{
Epidemiology of Endemic Nephropathy of Unknown Etiology in Latin America: A Review on Morbidity and Mortality
}

\section{Lopez AAV ${ }^{1^{*}}$, Barahona $\mathrm{K}^{2}$ and Guerra $\mathrm{EHC}^{3,4}$}

${ }^{1}$ Department of Physiology, Faculty of Medicine, University of San Carlos of Guatemala, Guatemala

${ }^{2}$ Aceite Olmeca, Occupational Safety and Health, Guatemala

${ }^{3}$ Faculty of Medicine, University of San Carlos of Guatemala, Guatemala

${ }^{4}$ Center for Clinical Epidemiology and Biostatistics, University of Pennsylvania, Philadelphia

*Corresponding author: Angel Alfonso Velarde Lopez, Department of Physiology, Faculty of Medicine, University of San Carlos of Guatemala, Guatemala, Tel: 011-502-53037578; E-mail: velarde13@gmail.com

Received date: Mar 18, 2018; Accepted date: Apr 08, 2018; Published date: Apr 13, 2018

Copyright: @ 2018 Lopez AAV, et al. This is an open-access article distributed under the terms of the Creative Commons Attribution License, which permits unrestricted use, distribution, and reproduction in any medium, provided the original author and source are credited.

\begin{abstract}
Endemic nephropathy disease unexplained by diabetes or hypertension is highly prevalent on countries of Latin America. The purpose of this review is to present a brief summary to analyze de epidemiologic data on morbidity and mortality as well as the etiology unexplained by diabetes and hypertension, with emphasis in studies from areas of sugarcane, heat stress or cotton plantation, to understand the contributing social and work factors. From our review we conclude that clinical trials are needed to elucidate the nephropathy unexplained by conventional risk factors in Guatemala, Honduras, Panama, and Mexico, and some other countries, from areas of sugarcane, heat stress or cotton plantation work. Regular monitoring assessment of heat stress during harvesting season needs to be implemented by labor ministries authorities in a way to regulate the compliance of each employer on measures they should take to prevent worker illnesses and death caused by heat stress. Although there is some evidence about hydration preventing nephropathy, large clinical trials are needed to determine the extent of supplemental hydration solutions and time interval to slow the loss of kidney function in areas of sugarcane, heat stress or cotton plantation work. Employers should take steps that help workers become acclimatized, gradually build up exposure to heat, especially workers who are new to working in the heat or have been away from work.
\end{abstract}

Keywords: Nephropathy; Latin America; Morbidity; Mortality; Epidemiology

\section{Introduction}

Since 1997, several regions in Latin America have seen a dramatic increase in rapidly progressive nephropathy unexplained by conventional risk factors such as diabetes and hypertension, and it has been concentrated in relatively young men, particularly sugarcane workers [1].

Our objective here is to review the prior published studies in population from areas of sugarcane, heat stress or cotton plantation, to understand the contributing social and work factors for this nephropathy of unknown etiology in Latin America. This information is intended to benefit future studies that need to be done in areas in which the disease has yet to be characterized like in Guatemala, Honduras, Panama and Mexico [2], as well as in some regions of Nicaragua [1], El Salvador and Costa Rica, 3 countries in which this nephropathy has been well documented [3-6]. We present here the prior published studies accrued by country, to understand which areas need more studies to characterize patterns and trends of this nephropathy to understand prevalence in populations that are less well studied or not identified as high risk, like women and adolescents. Clinical trials should forcefully target elucidating the cause of this nephropathy of unknown etiology in Latin America and promote interventions and simultaneously attract international funding for the problem.
Although there is some evidence about hydration preventing nephropathy [1], large clinical trials are needed to determine the extent of supplemental hydration solutions and time interval to slow the loss of kidney function in areas of sugarcane, heat stress or cotton plantation work.

\section{Morbidity of the Endemic Nephropathy Unrelated to Diabetes or Hypertension in Latin America}

\section{In El Salvador}

Between November 1999 to march of 2000 were admitted into a single hospital center 205 new dialysis patients, 135 patients (67\%) had unusual characteristics that were not associated with the known risk factors of diabetes, hypertension, primary glomerular diseases or obstructive uropathy, instead, the majority of them were male, farmers, residents of coastal areas or areas next to rivers and some years before had been exposed, without adequate protection, to agricultural insecticides or pesticides through their work [7].

In another study by 2012 in 256 men and 408 women (participation, 73\%) from 5 communities in El Salvador, of the men in the coastal communities $18 \%$ had reduced glomerular filtration rate (eGFR) $<60$ $\mathrm{mL} / \mathrm{min} / 1.73 \mathrm{~m}^{2}$, highest for coastal sugarcane and cotton plantation workers. The adjusted Odds Ratio (ORa) of decreased kidney function for 10 year increments of coastal sugarcane or cotton plantation work were 3.1 (95\% CI, 2.0-5.0) in men and 2.3 (95\% CI, 1.4-3.7) in women [3]. 


\section{In Guatemala}

While sugar cane production is not the only crop in Guatemala, it is the predominant and most economically important in the Southwest departments, the high temperatures and flat land needed for these plantations are only available in the Southwest. Dialysis enrollment rates were mapped using ArcGIS software, and showed to be higher in the Southwest, predominantly sugar cane area, peritoneal dialysis is the most common dialysis modality in all of Guatemala, but is more common in the Southwest (79.9\%) than the rest of the country $(75.7 \%$, $\mathrm{p}<0.01)$. may have a similar geographic distribution as Nicaragua and El Salvador, higher in the high temperature and sugar cane growing regions [5].

\section{In Nicaragua}

In 2010, a cross sectional study in 1096 participants from 5 villages of Nicaragua found a prevalence of $18 \%$ of abnormal serum creatinine levels (in men) and 5\% (of all women); in the mining/subsistence farming village, $26 \%$ and $7 \%$; banana/sugarcane, $22 \%$ and $6 \%$; fishing, $13 \%$ and $4 \%$; services, $0 \%$ and $1 \%$; and coffee, $7 \%$ and $0 \%$, of unknown origin, possibly environmental or occupational [4]. In another study by 2011, 771 individuals from 300 households participated in the prevalence study, 98 (12.7\%) of whom had reduced eGFR $<60 \mathrm{~mL} / \mathrm{min} /$ $1.73 \mathrm{~m}^{2}$, historically, cotton was the major crop in this region and the prevalence of chronic kidney disease (CKD) in Quezalguaque is 2.6 times greater among men than among women [8].

In 1997, Lopez et al. in an unpublished thesis report, evaluated hydro-electrolyte modifications in sugarcane workers in western Nicaragua after they were given rehydration solutions while harvesting sugarcane, they evaluated 15 workers supplied with an electrolytebalanced rehydration solution and an equal number of workers given regular tap water. More severe dehydration was found in $33 \%$ of the tap water group and only among $20 \%$ of the rehydration solution group. Ten years later, Dr. Solis Zepeda in an unpublished thesis report during the 2005/2006 harvest period, conducted a controlled clinical trial on the same working population in western Nicaragua to evaluate the impact of preventive measures used to avoid damage to renal function caused by heat, the intervention consisted in rehydration solution (treated group) or regular water (control group) intake, provided by the company they work for. He evaluated 218 workers who drank rehydration solutions and 187 workers who drank regular water; Glomerular filtration rate was significantly impaired in the control group, $-16 \mathrm{cc} / \mathrm{min}$ difference compared with the treated group -3.2 $\mathrm{cc} /$ min difference, $\mathrm{p}<0.001$. In a published study, a small group of 22 sugarcane workers were provided with more rehydration solutions and water during their work schedule, they were followed up for 15 days during working hours, from 6 am to $3 \mathrm{pm}$. Seven workers drank 7-8 L of liquid, improving their production. Output production increased significantly $(\mathrm{p}=0.005)$ among those best hydrated, from 5.5 to 8 tons of cut sugarcane per worker per day [1].

\section{In Costa Rica}

Sugarcane production has been hypothesized as a causal factor of chronic kidney disease epidemic in Central America, nonparticipatory observation and Wet Bulb Globe Temperatures (WBGT) according to Spanish NTP (Technical Prevention Notes) guidelines were utilized to quantify the risk of heat stress. Sugarcane harvesters carried out labor-intensive work with a metabolic load of $261 \mathrm{~W} / \mathrm{m}^{2}$ $(6.8 \mathrm{kcal} / \mathrm{min})$, corresponding to a limit value of $26^{\circ} \mathrm{WBGT}$ which was reached by 7:30 am on most days. After 9:15 am, OSHA recommendations would require that workers only work $25 \%$ of each hour to avoid health risks from heat [6], therefore, a large percentage of harvesters are experiencing heat illness throughout the harvest demonstrating an urgent need for improved workplace practices, particularly in light of climate change and the epidemic of chronic kidney disease prevalent in this population [9]. Workers in low and middle income tropical countries are likely at highest risk of excessive heat exposure as these countries are densely populated, have large informal work sectors and are expected to show substantial temperature increases due to global climate change [10].

\section{In Brazil}

Sugarcane harvesting has been associated with an epidemic of chronic kidney disease in Central America mainly affecting previously healthy young workers, this exploratory study aimed to assess the acute effects of burnt sugarcane harvesting on renal function among 28 healthy non-African Brazilian workers. All individuals decreased their estimated glomerular filtration rate by $\sim 20 \%$ at the end of the daily shift and $18.5 \%$ presented with serum creatinine increases consistent with acute kidney injury [11].

More formal studies are needed to characterize the nephropathy in Guatemala, Honduras, Panama and Mexico from areas of sugarcane, heat stress or cotton plantation work.

\section{Mortality from Nephropathy Unrelated to Diabetes or Hypertension in Latin America}

El Salvador has the highest overall mortality from kidney disease in the world, with Nicaragua and Honduras included in the 10 highest countries, most health researchers and public health practitioners are unaware of this epidemic [12]. El Salvador and Nicaragua, with mortality rates between 9 fold and 12 fold higher than reference countries, were the most affected. Statistical modeling suggests that the epidemic commenced around the mid-1970s, coinciding with important changes in modes of agricultural production [13]. During 1970-2012, age-adjusted mortality rates in the Guanacaste province of Costa Rica increased among men from 4.4 to 38.5 per 100000 vs. 3.6-8.4 in the rest of Costa Rica and among women from 2.3 to 10.7 per 100000 vs. 2.6-5.0 in the rest of Costa Rica, the male spatiotemporal patterns roughly followed sugarcane expansion in hot, dry lowlands with manual harvesting [14].

National CKD mortality rates among males show excess mortality in Nicaragua and El Salvador (66 and 64 per 100000, respectively), compared to Guatemala (16 per 100000), Panama (15 per 100000), Costa Rica (8 per 100000) and the United States of America (4 per 100000) [15].

\section{Etiology of the Endemic Nephropathy Unrelated to Diabetes or Hypertension in Latin America}

Although the etiology is still not clear, there is consensus among most researchers that the nephropathy in Latin America has an important occupational and environmental component and that physical exertion under heat stress is probably related to the disease. Continuous repetitive episodes of dehydration and heat stress may play an important role in the pathophysiology of the disease [16]. 
Citation: Lopez AAV, Barahona K, Guerra EHC (2018) Epidemiology of Endemic Nephropathy of Unknown Etiology in Latin America: A Review on Morbidity and Mortality. J Kidney 4: 167. doi:10.4172/2472-1220.1000167

Page 3 of 3

\section{Conclusion and Recommendation}

Large clinical trials are needed to determine the extent of supplemental hydration solutions and time interval to slow the loss of kidney function in areas of sugarcane, heat stress or cotton plantation work. Employers should take steps that help workers become acclimatized, gradually build up exposure to heat, especially workers who are new to working in the heat or have been away from work.

\section{References}

1. Delgado CO (2009) Heat stress assessment among workers in a Nicaraguan sugarcane farm. Glob Health Action 2: 2069.

2. Wesseling C, Crowe J, Hogstedt C, Jakobsson K, Lucas R, et al. (2014) Resolving the enigma of the mesoamerican nephropathy: A research workshop summary. Am J Kidney Dis 63: 396-404

3. Peraza S, Wesseling C, Aragon A, Leiva R, García-Trabanino RA, et al. (2012) Decreased kidney function among agricultural workers in El Salvador. Am J Kidney Dis 59: 531-540.

4. Torres C, Aragón A, González M, Jakobsson K, Elinder CG, et al. (2010) Decreased kidney function of unknown cause in Nicaragua: A community-based survey. Am J Kidney Dis 55: 485-496.

5. Laux TS, Barnoya J, Guerrero DR, Rothstein M (2015) Dialysis enrollment patterns in Guatemala: Evidence of the chronic kidney disease of non-traditional causes epidemic in Mesoamerica. BMC Nephrol 16: 54.

6. Crowe J, Wesseling C, Solano BR, Umaña MP, Ramírez AR, et al. (2013) Heat exposure in sugarcane harvesters in Costa Rica. Am J Ind Med 56: 1157-1164.

7. Trabanino RG, Aguilar R, Silva CR, Mercado MO, Merino RL (2002) Terminal nephropathy in patients of a reference hospital in El Salvador. Pan Am J Pub Health 12: 202-206.

8. O'donnell JK, Tobey M, Weiner DE, Stevens LA, Johnson S, et al. (2010) Prevalence of and risk factors for chronic kidney disease in rural Nicaragua. Nephrol Dial Transplant 26: 2798-2805.
9. Crowe J, Nilsson M, Kjellstrom T, Wesseling C (2015) Heat-Related symptoms in sugarcane harvesters. Am J Ind Med 58: 541-548.

10. Lucas RA, Epstein Y, Kjellstrom T (2014) Excessive occupational heat exposure: A significant ergonomic challenge and health risk for current and future workers. Extreme Physiol Med 3: 14.

11. Santos UP, Zanetta DMT, Terra-Filho M, Burdmann EA (2015) Burnt sugarcane harvesting is associated with acute renal dysfunction. Kidney Int 87: 792-799.

12. Ramirez-Rubio O, McClean MD, Amador JJ, Brooks DR (2013) An epidemic of chronic kidney disease in Central America: An overview. Postgrad Med J 89: 123-125.

13. Ordunez P, Nieto FJ, Martinez R, Soliz P, Giraldo GP, et al. (2018) Chronic kidney disease mortality trends in selected Central America countries, 1997-2013: Clues to an epidemic of chronic interstitial nephritis of agricultural communities. J Epidemiol Community Health 72: 280-286.

14. Wesseling C, Joode BVW, Crowe J, Rittner R, Sanati NA, et al. (2015) Mesoamerican nephropathy: geographical distribution and time trends of chronic kidney disease mortality between 1970 and 2012 in Costa Rica. Occup Environ Med 72 : 714-721.

15. Lozier M, Turcios-Ruiz RM, Noonan G, Ordunez P (2016) Chronic kidney disease of nontraditional etiology in Central America: A provisional epidemiologic case definition for surveillance and epidemiologic studies. Rev Panam Salud Publica 40: 294-300.

16. García-Trabanino R, Cerdas M, Madero M, Jakobsson K, Barnoya J, et al. (2017) Mesoamerican nephropathy: Brief review based on the Second Workshop of the Consortium for the study of the Epidemic of Nephropathy in Central America and Mexico (CENCAM). Latin Am Nephrol 14: 39-45. 